\title{
Effects of an outdoor education intervention on the mental health of schoolchildren
}

\author{
Per E Gustafsson, Anders Szczepanski, Nina Nelson and Per A Gustafsson
}

\section{Linköping University Post Print}

\section{Tweet}

N.B.: When citing this work, cite the original article.

This is an electronic version of an article published in:

Per E Gustafsson, Anders Szczepanski, Nina Nelson and Per A Gustafsson. Effects of an outdoor education intervention on the mental health of schoolchildren, 2011, Journal of Adventure Education and Outdoor Learning, 12(1), 63-79.

Journal of Adventure Education and Outdoor Learning is available online at informaworldTM:

http://dx.doi.org/10.1080/14729679.2010.532994

Copyright: Taylor \& Francis (Routledge): SSH Titles http://www.routledge.com/

Postprint available at: Linköping University Electronic Press http://urn.kb.se/resolve?urn=urn:nbn:se:liu:diva-70047 


\section{Effects of an Outdoor Education Intervention on the Mental Health of School Children}

Per E Gustafsson ${ }^{\mathrm{a},}$, Anders Szczepanski ${ }^{\mathrm{b}}$, Nina Nelson ${ }^{\mathrm{c}}$, Per A Gustafsson ${ }^{\mathrm{a}}$

${ }^{a}$ Dept of Public Health and Clinical Medicine, Family Medicine, Umeå University, SE-901

85 Umeå, Sweden

b Center for Outdoor Environmental Education, Dept of Arts, Craft and Design, Linköping University, SE-581 83 Linköping, Sweden

c Dept of Clinical and Experimental Medicine, Division of Pediatrics, Linköping University, SE-581 85 Linköping, Sweden

${ }^{\mathrm{d}}$ Dept of Clinical and Experimental Medicine, Division of Child \& Adolescent Psychiatry, Linköping University, SE-581 85 Linköping, Sweden

*Corresponding author: Per E Gustafsson, Dept of Public Health and Clinical Medicine, Family Medicine, Umeå University, SE-901 85 Umeå, Sweden. Phone no: +46 90785 3524, Fax no: +46 90776 883, E-mail: Per.E.Gustafsson@fammed.umu.se 
Author note

Acknowledgements: We thank Elin Allansson-Kjölhede for participation in the data collection as well as the staff at the participating schools. The study was financially supported by The Erik Johan Ljungberg Educational Fund, HAGS Aneby AB, The Swedish Medical Society/The Foundation of Söderström-Königska Sjukhemmet and the County of Östergötland. 
Author biographies

Per E Gustafsson, Ph.D., has in his dissertation within Child \& Adolescent Psychiatry studied psychosocial, psychiatric and physiological aspects of stress in childhood. Currently, his main area of interest is on life course epidemiology and specifically the long-term health consequences of adverse social conditions over the life course. E-Mail:

Per.E.Gustafsson@fammed.umu.se

Anders Szczepanski, Ph. Lic., has in his licentiate dissertation studied the variation of teachers' perceptions of outdoor education and the landscape as a learning environment. The study indicates a multiplicity of varied perceptions of the special nature of outdoor education and can thus be said to characterise this as richly diversified. E-Mail:

Anders.Szczepanski@liu.se

Nina Nelson, M.D., Ph.D., is associate professor in paediatrics and formerly head of the paediatric clinic at the University Hospital in Linköping, at present director of research and development in the county of Östergotland, Sweden. Her research interest began from within neonatology and cardiology, and has increasingly been focused on stress and health issues in the growing individual, and care givers and teachers, from biological, pedagogical and socioeconomical viewpoints. E-Mail: Nina.Nelson@lio.se

Per A Gustafsson, M.D. Ph.D., is associate professor in child and adolescent psychiatry and also works clinically as a child psychiatrist. His research field has mainly focused on mindbody interactions in children and adolescents, and its interplay with the immediate social environment, but also neuropsychiatric disorders in young people. E-Mail:

Per.A.Gustafsson@liu.se 


\begin{abstract}
This study aimed at examining the effects of an outdoor educational intervention on the mental health of school children. Two elementary schools participated $(N=230)$, one experimental school where the intervention was done, the other a reference school. Demographic questions and the Strengths and Difficulties Questionnaire were completed by the parents. An outdoor educational intervention was implemented at the experimental school, and the data collection was repeated after one year. The results point towards a small but non-significant improvement in mental health at the experimental school while adjusting for demographics. However, this effect was significantly moderated by gender: boys generally fared better than girls at the intervention school, relative to the reference school. The results indicate that it may be important to address gender issues when educational programs are implemented in schools.
\end{abstract}

Keywords: School Children, Outdoor Education, Response to Intervention, Mental Health, Gender 
Children spend most of their waking hours in school. It is therefore no surprise that the school environment affects the mental well-being of children (Anderman, 2002). The nature of this influence may be further understood from an ecological perspective. The school, much like the family and peer group, is an important developmental context for the child; a microsystem (Bronfenbrenner, 1979; Farmer \& Farmer, 1999). A microsystem is the web of relations between the individual and its environment, and constitutes a physical setting, where the participants engage in particular activities in particular roles for a particular period of time. The microsystems are themselves embedded in and influenced by a context; the mesosystem, which describes the interrelations of major Microsystems; the exosystem, which is the broader formal and informal social structure not directly containing the individual; and the macrosystem, which describes the general institutional patterns of the relevant culture or subculture (Bronfenbrenner, 1979).

There are several mechanisms through which the school as a microsystem may influence the mental well-being of the child (Farmer \& Farmer, 1999). First, at the level of exosystem or macrosystem, the educational context itself is influenced by structural factors such as stratification of school districts, funding source and special education needs. This stratification creates different microsystems where education takes place, and thus influences instructional aspects of the school (Gamoran, 1986) with social, psychological and behavioural consequences for the individual child . The school also influences children through the peer network (Farmer \& Farmer, 1999), which constitutes a microsystem for school children that considerably overlaps with the school microsystem. These mediating and moderating roles of the school environment may be a partial explanation as to why early problems in school (Kellam, Ling, Merisca, Brown, \& Ialongo, 1998; Masten, 2003; Rutter, 1980) or negative perceptions about the school (Andersson \& Strander, 2004) may predict later maladjustment. 
This importance of the school for child development stresses the need for a school environment that is supportive for the child and promotes mental health and well-being. Because of this, as well as for administrative reasons, the school provides a physical and organizational basis in which preventive interventions may be undertaken (Cowen \& Durlak, 2000).

There is a multitude of school-based mental health programs, and the growing research field of school mental health continuously evaluate the effectiveness of different programs to reduce the “research-practice gap” (Durlak, 1995; Durlak \& Wells, 1997). Most of these programs focus on the individual (Durlak, 1995). Examples of such individual-centred interventions are affective education, directed at increasing children’s awareness and expression of feeling and the causes of behaviour, and interpersonal problem-solving training, focusing on developing cognitive skills to recognize interpersonal problems and effective approaches to solve them (Durlak \& Wells, 1997). Less common are interventions aimed at changing the environment, even though there are strong theoretical grounds that environment-centred interventions may produce broader psychosocial benefits for children (Berryhill \& Prinz, 2003; Bronfenbrenner, 1979). Most commonly, environment-centred interventions focus on improving the psychosocial classroom milieu (Durlak \& Wells, 1997). For example, an intervention directed at reducing childhood aggression described by Hawkins et al. (1991) consisted of, in addition to parent training, teacher training in the use of proactive classroom management, cognitive social skills and interactive teaching methods. Others have however employed even more ambitious programs involving several actors (teachers, administrators, mental health professionals and parents) to change the structural and functional aspect of the school (Comer, 1985), or implementing a child development centre as a completely new setting supporting behavioural adjustment in school (Johnson \& Breckenridge, 1982). 
Outdoor education is an environment-focused educational approach characterized by action-centred and thematic learning processes, often related to outdoor activities (Dahlgren \& Szczepanski, 1998). It aims to foster learning through the interactions between emotions, actions and thoughts, based on practical observation in authentic situations (Dahlgren \& Szczepanski, 2004). This perspective on knowledge and learning in which a varied learning environment is given importance contrasts with the traditional educational system, which is based on theoretical knowledge taught in a classroom setting, limiting these interactions.

Outdoor education has the potential to become an integrative, complementary education form in a pragmatic and progressive pedagogy tradition that can offer students and teachers opportunities to learn based on observations and experiences in authentic situations. Moreover, with outdoor education, a more movement-intensive form of learning is created (Grahn, Mårtensson, Lindblad, Nilsson, \& Ekman, 1997). Although the literature on the psychological effects of physical activity in youth is under-developed and mostly concerns adolescents, available results suggest beneficial effects on self-esteem (Ekeland, Heian, Hagen, Abbott, \& Nordheim, 2004), depression and anxiety (Larun, Nordheim, Ekeland, Hagen, \& Heian, 2006). These psychological gains may be partly mediated by a buffering effect of exercise on stress exposure (J. D. Brown \& Lawton, 1986; J. D. Brown \& Siegel, 1988; Norris, Carroll, \& Cochrane, 1992). The stress-buffering effects could possibly be explained by counter conditioning mechanisms, where initially negative stimuli (exercise) obtain positive motivational properties through the association to other positive stimuli (e.g., social interaction) and influence general stress tolerance (Salmon, 2001). School policies have been shown to be important determinants in accomplishing increased physical activity in children (Ferreira, et al., 2007; Gordon-Larsen, McMurray, \& Popkin, 2000), which makes school-based interventions a particularly promising prospect. 
In addition to the potential beneficial effects of physical activity, a growing body of literature also suggests that the natural environment has profound effects on the well-being, particularly in children due to their greater plasticity or vulnerability (Wells \& Evans, 2003). A study of ten schools and a state-wide program by the National Environmental Education and Training Foundation (2000) found that when schools use the context of local areas and naturalized schoolyards in their instructional practices, academic performance improves in reading, math, science, social studies and writing. A study of 40 schools in California that used the natural environment as "an integrated context of learning" with hands-on, projectbased learning found that student performance improved in standardized test scores, grade point average, willingness to stay on task, adaptability of different learning styles and problem solving (Leiberman \& Hoody, 1998). Examples of beneficial effects for child development and well-being of experiences in nature are improved cognitive functioning (Wells, 2000) and ability to apply self-disciplined behaviour (Taylor, Kuo, \& Sullivan, 2002), better psychological well-being and capacity to cope with adversity (Wells \& Evans, 2003) and a reduction in anti-social behaviour such as violence, bullying, vandalism and littering a drop in absenteeism (Coffey, 2001; Moore \& Cosco, 2000). Thus, the potential benefits of outdoor education for children's well-being can be a combined effect of both increased physical activity and its situation in the natural environment.

Although various educational changes are common in the schools, few are systematically evaluated with respect to their potential impact on the mental health of the children; when the impact of various school factors is examined the common main focus is the effect on achievement (Anderman, 2002; Lipsey \& Wilson, 1993; Watt, 2003). The benefit of children's well-being is a factor seldom examined but rather assumed when new programs or other organizational or pedagogical changes are implemented (Cowen \& Durlak, 2000). In a recent systematic review (Gustafsson, et al., 2010, pp. 155-156) it was concluded 
that the amount of research which investigates relations between different aspects of schooling and mental health is limited, and particularly so research concerning organizational factors and different educational factors, such as teaching methods and activities. However, a relatively large enough amount of research concerned with relations between mental health on the one hand, and the individual students' academic and social achievements and failures on the other exists. The reviewers major conclusions were that academic achievement and mental health are reciprocally related; that early school failures and in particular reading difficulties cause internalizing and externalizing mental health problems; that problems of academic achievement and mental health tend to be stable over time; that investment of time and effort in schoolwork without achieving expected outcomes is related to development of depression; that relations with peers and teachers are involved in establishing the negative effects of school failure on mental health, but relations with peers and teachers can also protect against development of mental health problems. Thus, there is obviously a potential that educational measures can influence psychological well-being in school children.

When outdoor educational programs are quantitatively evaluated, low-constraint designs such as post-test or pre-test-post-test designs are most common. Of these, the most frequent outcome measures of well-being are self-concept, self-confidence or locus of control (Neill \& Richards, 1998). The mental well-being of the child from a psychiatric perspective has not been examined in this context. Even when improved mental health is not the explicit aim of the intervention, it is an important factor to consider when an intervention is being implemented in a school. For example, it would be beneficial to develop and evaluate nontraditional interventions that are relevant both to the needs of the educational system as well as the mental health field (Ringeisen, Henderson, \& Hoagwood, 2003). Moreover, any intervention that fundamentally changes an important microsystem likely affects the wellbeing of the child, for better or for worse. Therefore, in addition to the specific psychological 
gains of increased physical activity, a pervasive general change in the school environment is also interesting to study from a mental health perspective.

However, activity in the natural outdoor environment should not be expected to be gender-neutral, and it has been argued that girls and boys gain qualitative different experiences from it (Ärlemalm-Hagsér, 2006). There is also a debate about whether there are gender role differences with respect to the emphasis on movement present in outdoor education (Ärlemalm-Hagsér, 2006). Moreover, girls and boys differ across childhood with respect to type and level of psychiatric problems presented (Rutter, Caspi, \& Moffitt, 2003). Therefore, gender is an important aspect to consider when studying the mental health impact of outdoor education.

The present study is an evaluation of the effects of an outdoor educational intervention on the mental health of school children, age 6 to 12 . The intervention is thus evaluated as a universal, environment-centred primary prevention intervention of mental health. We aimed at investigating the effect on general as well as specific dimensions of mental health, as well as the trait-treatment effect of gender.

\section{Method}

\section{Participants and Procedures}

This study employed a quasi-experimental non-equivalent groups design. The recruitment basis consisted of two elementary schools (preschool to grade 6) in the Municipality of Linköping, Sweden. One school (the intervention school) was situated in the urban fringe of the city of Linköping, while the other school (the reference school) was located in the city. The data collection was part of a study concerning biological and psychosocial aspects of stress, approved by the Local Ethics Committee. First, the principals of the schools were informed about the study and asked about participation of the schools. Next, written and oral information was given individually to the children and their parents 
who were offered participation. Informed consent forms and questionnaires were issued to the parents, and were sent in to the research group by mail or were collected at the schools. Two waves of reminder telephone calls were made to the parents who had not given any decision about participation. During the following year a pedagogical intervention, described below, was carried out at one of the schools (“School 1") while the other school ("School 2") acted as a reference school.

One year after the initial data collection, a follow-up was accomplished. The time frame 12 months was chosen according to practical circumstances at the participating schools. The procedures described above about information to the parents and children and the data collection, were repeated. For practicality and for satisfying other aims of the study, all children at the schools where included at both measuring points.

At the first data collection, Time 1, 342 out of 417 children participated, and 334 Strengths and Difficulties Questionnaires (SDQ, below) were collected. The second year, Time 2, the sample was somewhat smaller and 315 out of 376 children participated with 278 questionnaires collected. From time 1 to time 2 the oldest children had begun a new grade at new schools and new preschoolers had entered each school. Hence, the effective sample participating both at time 1 and time 2 consisted of 121 children at school 1 and 109 at school 2, totalling 230 children. There were 106 girls and 124 boys. The mean age at time 1 was 8.3 years (range 6-11). Demographic information by school at time 1 is shown in Table 1. Children in School 1 were significantly but marginally older than school 2. The sociodemographic distributions differed between the schools, school two having a substantially higher proportion of immigrants and low-SES families.

Pedagogical Intervention

Outdoor education (Dahlgren \& Szczepanski, 1998; Humberstone, Brown, \& Richards, 2003; Szczepanski, 2008) is an approach which aims to foster learning through the interplay 
between experience and reflection, based on practical observation in authentic situations. The pedagogical intervention entailed education of the teachers according to an outdoor educational perspective. Didactic sessions in the out-of-doors were held during the 6 months following the initial data collection, in total about 15 days of education. Two of these sessions consisted of whole working days while the rest mainly were held from 2pm-6pm in the afternoon.

The teachers were introduced to exercises related to the national elementary school curricula in language, mathematics, natural sciences, arts, music, drama and physical education. The aim was to give the teachers insights in outdoor educational methods directly applicable in a physically active instructional setting located outside the traditional classroom environment (Dahlgren, 2007; Dahlgren \& Szczepanski, 2004). This resulted in the pupils being taught the different subjects outdoor for at least 1h per school day. All classes were gender-mixed and were held by the regular teachers. Teachers at the intervention school had an interest in outdoor education and in their ordinary teaching sometimes used outdoor education methods before the intervention started. However, there was no formal pilot study done.

School work at the reference school employed traditional methods where all education was book-based and consisted of paper-and-pencil work in the indoor classroom environment. Outdoor education was used at the intervention school as a contrasting type of didactic method. At the intervention school, material from the natural environment was used as teaching material and the teaching was taking place in the outdoor environment. As an illustration from the mathematics lectures, branches, stones and cones were used as examples of geometrical forms. Similarly, in language classes the children made use of objects from nature and culture in their local environment to illustrate grammatical concepts (adjectives, nouns and verbs), exemplified by the sentences 'The hard stone is rolling on the asphalt' and 
'The thin leaf floats through the air down to the ground'. For this specific activity the children themselves participate and physically act with stones and the leaf; the whole body in motion is a part of the education process, and is an example of how learning in the intervention school was performed in a more movement intensive manner, based on the green context rather than on the classroom context. Similarly, to learn key concepts in geography lectures items in the outdoor environment, e.g. branches, stones, cones and ropes, were used to implement maps of Sweden and Europe with. Children had to create the map through the use of local landscape topography and experience the three-dimensional landscape model that they themselves created and then reflected on, discussed and argued within the study group and with the teacher. As an illustrative contrast, in the reference school the same subject was taught through traditional methods with paper and pencil in a two-dimensional way in the learning environment of the classroom

Demographics

A sociodemographic form about the parents' education and occupation, country of origin and family composition was gathered from the parents. Classification of socioeconomic status (SES) was derived from parents’ occupation, using a three-graded scale (Statistics Sweden, 1984). We included parents granted an early retirement and those unemployed together with skilled and unskilled workers in the lowest SES group. Children were defined as belonging to an immigrant family if at least one of the parents was born outside Scandinavia. The majority of the immigrants came from the Middle East.

\section{Outcome measure}

As a measure of mental health we used The Strengths and Difficulties Questionnaire (SDQ) (Goodman, 2001; Goodman \& Scott, 1999). The SDQ was for each child completed by their parents (parent-version). Parents were chosen as principal raters since they, in contrast to the teachers, were not directly involved in the intervention and thus could be 
expected to provide less biased measures of the mental health of the children. Although teacher ratings originally were intended to complement this primary assessment, the teachers at the reference school declined the assessment at Time 2. The SDQ is a 25-item screening instrument for general psychiatric symptoms in children and adolescents and is well-validated for different populations, including Swedish (Malmberg, Rydell, \& Smedje, 2003; Smedje, Broman, Hetta, \& von Knorring, 1999). It takes about 20 minutes to complete. SDQ generates five subscales with 5 items each: emotional symptoms, conduct problems, hyperactivity/inattention, peer problems and prosocial behaviour. The problem scales (all except prosocial behaviour) are summed up to form a total difficulties score. We used both the total difficulties score and the separate subscales as time-dependent variables in the analysis. See Table 2 for descriptive information of the SDQ total score and subscales, separated according to time, school and gender. The SDQ scores of the total sample approximately matched the Swedish standardized norms of the questionnaire (Smedje, et al., 1999), with the intervention school scoring slightly lower and the reference school slightly higher problem scores compared to the norms..

\section{Statistical Analysis}

To examine demographic differences between the schools, independent samples t-test and $\chi^{2}$-test were used.

To test for stochastic significance, we carried out a series of $2 \times 2 \times 2$ full factorial split-plot ANOVAs (time: pre-assessment vs. one-year follow-up SDQ score, school (condition): School 1 (intervention) vs. school 2 (reference), gender (trait): girls vs. boys). As the time variable we first used the Total difficult score of the SDQ, and subsequently in separate models, the subscales of SDQ (emotional symptoms, conduct problems, hyperactivity/inattention, peer problems and prosocial behaviour). Since the schools differed substantially regarding demographics, socioeconomic status and immigrant parents were 
included as covariates in the models. Exact $p$ values are reported except $p>.10$, which is reported as ns (not significant).

To indicate the strength and direction of the intervention effect, as well as the influence of gender, effect sizes (ES) with similar metric as the well-used Cohen's $d$, were calculated,

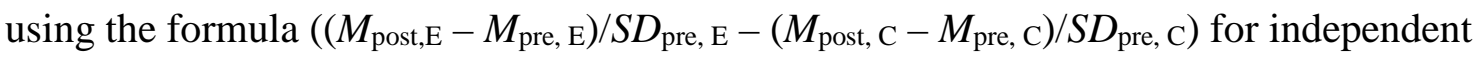
groups pretest-posttest design (Morris \& DeShon, 2002). Effect size for main and interaction effects are reported as partial $\eta^{2}$, adjusted for covariates.

Although the sample was too small to allow a detailed examination of the possible effects of age, this was explored in additional analyses. The analyses for total problems as well as the subscales were re-run with a two-level age variable (6-8 years vs. 9-11 years) including main and interaction effects. The results of these analyses indicated that age did not influence the results substantially (age effects ps $>.05$, data not shown). Therefore, only the analyses without age are reported in the results section.

\section{Results}

Our first aim was to investigate if the intervention impacted on mental health. The overall change in mental health problems indicated a more positive development for the children in the intervention school, with effect size $(E S)=.24$ for total difficulties score, .37 for emotional symptoms, .12 for conduct problems, .002 for hyperactivity, .26 for peer problems and -.05 for prosocial behaviour. However, when adjusting for demographics, the Time $\times$ School effect was non-significant for total difficulties as well as for all SDQ subscales (all ps $>.10$ and $\eta^{2} \mathrm{~s}<.01$, data not displayed), indicating that the intervention did not have an overall effect on mental health.

Our second aim was to examine if the impact of the intervention was dependent of gender. The effect of the intervention differed between boys and girls, as displayed by a significant Time $\times$ School $\times$ Gender interaction effect for total difficulties score $\left(p=.001, \eta^{2}\right.$ 
$=.049$ ). This corresponded to similarly significant interaction effects for the emotional symptoms $\left(\mathrm{p}=.044, \eta^{2}=.018\right)$, conduct problems $\left(\mathrm{p}=.003, \eta^{2}=.040\right)$ and hyperactivity $(\mathrm{p}$ $\left.=.005, \eta^{2}=.036\right)$ subscales, but non-significant effects for peer problems or prosocial behaviour. As summarized in Table 2 and 3, this display of a trait-treatment effect was generally numerically explained by a decrease in mental health problems for boys at the intervention school, coupled with a slight increase or no substantial difference for girls, as compared to the reference school.

\section{Discussion}

This study examined the effect of a pedagogical intervention on different dimensions of the mental health of school children within the time frame of one year. We found no evidence for a general mental health effect of the intervention. However, we found a significant differential effect on boys and girls; while boys at the intervention school generally displayed a decrease in mental health problems, compared to the reference school, the girls at the intervention school rather showed a non-change in mental health problems. It should be noted that the intervention school (for practical reasons) was situated outside the city area, while the reference school was in a typical urban school milieu. It seems probable that the outdoor education program would have meant much more change for the children if the intervention had been done in the urban school. That we found some favourable effects despite this and the fact that the pupils at the intervention school had less psychiatric symptoms at baseline supports the notion that outdoor education possibly could be beneficial for school children's mental health.

The trait-treatment interaction is best described as a more positive effect of the intervention for boys than for girls. This is an important result since it indicates that the intervention under study may be more beneficial for the mental well-being of boys than girls. That the girls’ psychiatric health was not improved could be compared to that academic 
achievement problems have been shown to cause internalizing mental health problems for females. Internalizing and externalizing mental health problems also have negative effects on academic achievement through mechanisms that are partly age- and gender-specific (Gustafsson, et al., 2010, pp. 77-78).

We did not do any systematic data collection about the social dynamics of the elements of the intervention or the children's perceptions of it. It has however previously been indicated that boys engage in more physical activity than girls, and that school-based physical activity interventions may be more appreciated by boys (Ridgers, Stratton, \& Fairdough, 2006). Furthermore, boys generally report more positive perceptions about their physical capabilities than girls due to the nature of physical activity (Lee, Carter, \& Xiang, 1995); physical education is typically a stereotypical, "gendered”, practice (Azzarito \& Solomon, 2005; D. Brown, 2005). Perhaps these conceptions are also reproduced in other activityfocused educational situations. Hopefully, future studies will examine the possible gender effect in outdoor education and the reasons thereof.

In a review of prevention programs for children, Durlak \& Wells (1997) reported a mean effect size of fifteen school-based, environment-focused programs of 0.35 (Durlak \& Wells, 1997). A further breakdown in problems versus competencies outcome yielded a significant mean effect size for studies with problems as outcome of 0.26 . This subgroup of intervention programs is comparable to the present study intervention, as is the estimation of effect size. This suggests that the pedagogical intervention reported here may be similarly effective as environment-focused mental health programs, although we did not find any stochastic evidence when controlling for the demographic characteristics of the samples.

The beneficial effects of outdoor and adventure programs have been documented before. In a comprehensive review (Hattie, Marsh, Neill, \& Richards, 1997), the authors reported a mean effect size across all studies of 0.34 . This, though, is a very heterogeneous 
group of studies regarding study design, sample interventions and intervention characteristics, and outcome measures, which makes direct comparison dubious as best.

\section{Limitations}

There are several methodological issues that limit the interpretation of the results. We employed a quasi-experimental design with non-randomized groups. The two schools included in the study were situated in areas with distinctly different socioeconomic and ethnical composition. The intervention school was located in a small urban fringe community in physical proximity to the woods and the families were mainly from the middle class and with no exception of Swedish heritage. Apparently, the children who participated in the intervention were from an environmentally and socially privileged area. As expected from this, the children at the intervention school scored lower on the SDQ than the Swedish norms (Smedje, et al., 1999) and lower than the reference school at baseline. These conditions suggest that the settings might not be compared without difficulty and are suboptimal circumstances when studying the effect of an intervention. Randomization at the individual level was obviously not possible as the pedagogical intervention was school-, not individual-, based. To take these differences into consideration, we adjusted for demographic factors in our analyses. An alternative would have been more stringent balancing of important confounders such as SES or ethnicity in our choice of schools, although this strategy might be difficult to successfully implement in practice.

These threats to the internal validity make it difficult to confidently attribute the changes to the intervention. However, in examining the reported effect sizes of interventions in the behavioural sciences, Lipsey et al (1993) found that there was at least no obvious bias towards higher effect size estimates in study designs of lower constraint, as long as a comparison group was used. The bias towards higher effect size was on the other hand evident in single-group comparisons (Lipsey \& Wilson, 1993). In the more specifically fitting 
field of primary prevention mental health program for youth, Durlak \& Wells (1997) did not find any systematic difference in mean effect size between randomized and non-randomized designs. Moreover, it should be noted that the schools indeed were comparable regarding several other important aspects, such as being located in the same municipality in Sweden and the children were of similar age. Still, this baseline difference between the schools is a caveat which one should bear in mind when interpreting the findings and generalizing to other settings.

In the Swedish school system the children remains in the same class throughout grades 0 to 6 , thus the children in the study did not change peers or school. The teacher is changed between grade 0 and 1 and between grade 3 and 4 . Thus the likely impact of the children changing grades on the outcome measures is judged as small. Moreover, the employment of a quasi-experimental design ascertained that any independent effect of changing grade was considered by the design. Although the present sample was too small to reliably examine results by age, exploratory analyses did not suggest that results varied substantially by age.

Another limitation is that we had only rudimentary control of the concrete impact on the school microsystem the intervention led to - how weak or strong the experimental contrasts actually were. This makes it difficult to attribute the changes to the intervention or to explain the exact components that supposedly contributed to the change.

As a time-frame of one year was chosen due to practical constraints, the outdoor education intervention obviously thus had had quite a short time period during which it could have influenced the mental health of the children. This rather short duration of exposure would be expected to reduce the estimated strength of effect.

A generalized placebo effect (Lipsey \& Wilson, 1993) is a possible contribution to the measured general beneficial effects of the intervention; that is, the effect is not specific to the intervention. While this clearly is possible, there are two arguments against it having any 
great impact on the results. First, there was not a general positive effect on the children but a differential effect by gender. Second, we used parental ratings of their own children’s symptoms. Compared to other possible informants such as the teachers and the children themselves, the parents were the least involved in the intervention, and can therefore be considered relatively independent and unbiased informants.

\section{Strengths of the study}

Albeit the methodological caveats, the study has several strengths as well. The mental health effect of changes in the school is a poorly studied area and there is great need for knowledge. Although the groups were in many aspects very different, the use of a control group still has merits beyond the use of pretest-posttest design. For example, especially when studying children that are developing, it is very important to control for maturing effects, especially in combination with gender (Rutter \& Taylor, 2002; Sameroff, 2000). The two groups were of roughly the same age and gender distribution, so this effect was controlled for.

Another strength of the study is the relative large sample, contributing to confidence in the estimates. Small samples $(\mathrm{n}<100)$ has been found combine to upward bias of effect size estimates, although the nature of this bias is speculative (Lipsey \& Wilson, 1993). Our measure of outcome, SDQ, is a well-used and psychometrically sound measure of children's symptoms, designed to be used as a screening instrument. The use of a standardized outcome measure have been shown to be a significant validity issue in similar studies (Durlak \& Wells, 1997). Likewise, the focus of preventive interventions on general emotional and behavioural problems instead of specific disorders has been advocated for (Durlak \& Wells, 1997). The choice of parents as informants was, as mentioned above, sensible since they were not directly affected by the intervention. The follow-up time of one-year is, within the context 
of the research field, a comparatively long time (Durlak, 1995), which suggests that there might be mental health effects beyond the immediate effects of the program.

The problems of generalizability of the results have been addressed above. However, the initiative to this intervention came from the educational field, and was formulated according to the contextual needs of the school system (Ringeisen, et al., 2003) by providing training for the teachers in developing their professional skills and thereby developing the learning environment at the school. Thus, the intervention focused on the teaching and learning practices involved in the core responsibility of the school system as an educational institution. This is an argument in favour of the applicability of such a program, any beneficial mental health effect aside.

Conclusions and Directions for Future Research

This evaluation of an outdoor educational intervention demonstrates trait-treatment interactions represented by moderate positive overall mental health effects for boys with small to moderate positive effects on specific mental health dimensions, but an inconclusive effect for girls. These results signify that gender may be an important characteristic to address when educational programs are evaluated. The reason for this gender difference also needs to be examined further. Particularly important is concern with gender issues in program development to avoid educational programs being principally designed to meet boys' needs, at the cost of girls’ needs. 


\section{References}

Anderman, E. M. (2002). School effects on psychological outcomes during adolescence. Journal of Educational Psychology, 94(4), 795-809.

Andersson, B.-E., \& Strander, K. (2004). Perceptions of School and Future Adjustment to Life: A longitudinal study between the ages of 18 and 25. Scandinavian Journal of Educational Research, 48(5), 459-476.

Azzarito, L., \& Solomon, M. A. (2005). A reconceptualization of physical education: The intersection of gender/race/social class. Sport, Education and Society, 10(1), 25-47.

Berryhill, J. C., \& Prinz, R. J. (2003). Environmental interventions to enhance student adjustment: implications for prevention. Preventive Science, 4(2), 65-87.

Bronfenbrenner, U. (1979). The ecology of human development: Experiments by nature and design. Cambridge: Harvard University Press.

Brown, D. (2005). An economy of gendered practices? Learning to teach physical education from the perspective of Pierre Bourdieu's embodied sociology. [Journal; Peer Reviewed Journal]. Sport, Education and Society, 10(1), 3-23.

Brown, J. D., \& Lawton, M. (1986). Stress and well-being in adolescence: the moderating role of physical exercise. Journal of Human Stress, 12(3), 125-131.

Brown, J. D., \& Siegel, J. M. (1988). Exercise as a buffer of life stress: a prospective study of adolescent health. Health Psychology, 7(4), 341-353.

Coffey, A. (2001). Transforming School Grounds. In T. Grant \& G. Littlejohn (Eds.), Greening School Grounds: Creating Habitats for Learning. Toronto: Green.

Comer, J. P. (1985). The Yale-New Haven Primary Prevention Project: a follow-up study. $J$ Am Acad Child Psychiatry, 24(2), 154-160.

Cowen, E. L., \& Durlak, J. A. (2000). Social policy and prevention in mental health. Development and Psychopathology, 12(4), 815-834. 
Dahlgren, L.-O. (2007). Utomhuspedagogik som kunskapskälla: närmiljö blir lärmiljö [Outdoor education as source of knowledge]. Lund: Studentlitteratur.

Dahlgren, L.-O., \& Szczepanski, A. (1998). Outdoor education - literary education and sensory experiennce. An attempt at defining the identity of outdoor education. Kisa, Sweden: Kinda Education Center.

Dahlgren, L.-O., \& Szczepanski, A. (2004). Rum för lärande - några reflexioner om utomhusdidaktikens särart [Room for learning - some reflections on the distinctive nature of outdoor didactics]. In L. I., P.-O. Wickman \& A. Wohlin (Eds.), Utomhusdidaktik (pp. 9-23). Lund: Studentliteratur.

Durlak, J. A. (1995). School-based prevention programs for children and adolescents (Vol. 34). Thousand Oaks, CA: Sage.

Durlak, J. A., \& Wells, A. M. (1997). Primary prevention mental health programs for children and adolescents: a meta-analytic review. American Journal of Community Psychology, 25(2), 115-152.

Ekeland, E., Heian, F., Hagen, K. B., Abbott, J., \& Nordheim, L. (2004). Exercise to improve self-esteem in children and young people. Cochrane Database Syst Rev(1), CD003683.

Farmer, E. Z. M., \& Farmer, T. W. (1999). The role of schools in outcomes for youth: implications for children's mental health services research. Journal of Child and Family Studies, 8(4), 377-396.

Ferreira, I., van der Horst, K., Wendel-Vos, W., Kremers, S., van Lenthe, F. J., \& Brug, J. (2007). Environmental correlates of physical activity in youth - a review and update. Obesity Review, 8(2), 129-154.

Gamoran, A. (1986). Intructional and institutional effects of ability grouping. Sociology of Education, 59(4), 185-198. 
Goodman, R. (2001). Psychometric properties of the strengths and difficulties questionnaire. J Am Acad Child Adolesc Psychiatry, 40(11), 1337-1345.

Goodman, R., \& Scott, S. (1999). Comparing the Strengths and Difficulties Questionnaire and the Child Behavior Checklist: is small beautiful? J Abnorm Child Psychol, 27(1), $17-24$.

Gordon-Larsen, P., McMurray, R. G., \& Popkin, B. M. (2000). Determinants of adolescent physical activity and inactivity patterns. Pediatrics, 105(6), E83.

Grahn, P., Mårtensson, F., Lindblad, B., Nilsson, P., \& Ekman, A. (1997). "Ute på dagis" Hur använder barn daghemsgården? [Outside at the day care center- how do children play outside] Alnarp: Movium förlag.

Gustafsson, J.-E., Allodi, M. W., Alin Åkerman, B., Eriksson, C., Eriksson, L., Fischbein, S., et al. (2010). School, learning and mental health: a systematic review. Stockholm: Health Committee, Royal Swedish Academy of Sciences.

Hattie, J., Marsh, H. W., Neill, J. T., \& Richards, G. E. (1997). Adventure education and outward bound: out-of-class experiences that make a lasting difference. Review of Educational Research, 67(1), 43-87.

Hawkins, J. D., Von Cleve, E., \& Catalano, R. F., Jr. (1991). Reducing early childhood aggression: results of a primary prevention program. J Am Acad Child Adolesc Psychiatry, 30(2), 208-217.

Humberstone, B., Brown, H., \& Richards, K. (2003). Whose journeys?: the outdoors and adventure as social and cultural phenomena: critical explorations of relations between individuals, "others" and the environment. Penrith: The Institute for Outdoor Learning. 
Johnson, D. L., \& Breckenridge, J. N. (1982). The Houston Parent--Child Development Center and the primary prevention of behavior problems in young children. Am J Community Psychol, 10(3), 305-316.

Kellam, S. G., Ling, X., Merisca, R., Brown, C. H., \& Ialongo, N. (1998). The effect of the level of aggression in the first grade classroom on the course and malleability of aggressive behavior into middle school. Development and Psychopathology, 10(2), 165-185.

Larun, L., Nordheim, L. V., Ekeland, E., Hagen, K. B., \& Heian, F. (2006). Exercise in prevention and treatment of anxiety and depression among children and young people. Cochrane Database Syst Rev, 3, CD004691.

Lee, A. M., Carter, J. A., \& Xiang, P. (1995). Children's conceptions of ability in physical education. [Journal; Peer Reviewed Journal]. Journal of Teaching in Physical Education, 14(4), 384-393.

Leiberman, G., \& Hoody, L. (1998). Closing the Achievement Gap: Using the Environment as an Integrated Context for Learning San Diego, California: State Education and Environmental Roundtable.

Lipsey, M. W., \& Wilson, D. B. (1993). The efficacy of psychological, educational, and behavioral treatment. Confirmation from meta-analysis. American Psychologist, 48(12), 1181-1209.

Malmberg, M., Rydell, A. M., \& Smedje, H. (2003). Validity of the Swedish version of the Strengths and Difficulties Questionnaire (SDQ-Swe). Nord J Psychiatry, 57(5), 357363.

Masten, A. M. (2003). Commentary: developmental psychopathology as a unifying context for mental health and education models, research, and practice in schools. School Psychology Review, 32(2), 169-173. 
Moore, R., \& Cosco, N. (2000). Developing an Earth-Bound Culture Through Design of Childhood Habitats. Paper presented at the Conference on People, Land, and Sustainability: A Global View of Community Gardening.

Morris, S. B., \& DeShon, R. P. (2002). Combining effect size estimates in meta-analysis with repeated measures and independent-groups design. Psychological Methods, 7(1), 105125.

National Environmental Education \& Training Foundation (2000). Environment-based Education. Washington DC: The National Environmental Education \& Training Foundation.

Neill, J. T., \& Richards, G. E. (1998). Does outdoor education really work? A summary of recent meta-analyses. Australian Journal of Outdoor Education, 3(1), 1-9.

Norris, R., Carroll, D., \& Cochrane, R. (1992). The effects of physical activity and exercise training on psychological stress and well-being in an adolescent population. Journal of Psychosomatic Research, 36(1), 55-65.

Ridgers, N. D., Stratton, G., \& Fairdough, S. J. (2006). Physical Activity Levels of Children during School Playtime. [Journal; Peer Reviewed Journal]. Sports Medicine, 36(4), 359-371.

Ringeisen, H., Henderson, K., \& Hoagwood, K. (2003). Context matters: schools and the "research to practice gap" in children's mental health. School Psychology Review, 32(2), 153-168.

Rutter, M. (1980). School influences on children's behavior and development: the 1979 Kenneth Blackfan Lecture, Children's Hospital Medical Center, Boston. Pediatrics, 65(2), 208-220. 
Rutter, M., Caspi, A., \& Moffitt, T. E. (2003). Using sex differences in psychopathology to study causal mechanisms: unifying issues and research strategies. J Child Psychol Psychiatry, 44(8), 1092-1115.

Rutter, M., \& Taylor, E. (2002). Child and Adolescent Psychiatry (4th ed.). Bath: Blackwell Science Ltd.

Salmon, P. (2001). Effects of physical exercise on anxiety, depression, and sensitivity to stress: a unifying theory. Clinical Psychology Review, 21(1), 33-61.

Sameroff, A. J. (2000). Developmental systems and psychopathology. Development and Psychopathology, 12(3), 297-312.

Smedje, H., Broman, J. E., Hetta, J., \& von Knorring, A. L. (1999). Psychometric properties of a Swedish version of the "Strengths and Difficulties Questionnaire". European Child and Adolescent Psychiatry, 8(2), 63-70.

Statistics Sweden (1984). Swedish socioeconomic classification. Reports on statistical coordination 1982:4. Stockholm.

Szczepanski, A. (2008). Knowledge Through Action: Teachers'perceptions of the landscape as a learning environment. Linköping: Department of Culture and Communication, National Center for Outdoor Education, Linköping University.

Taylor, A. F., Kuo, F. E., \& Sullivan, W. C. (2002). Views of Nature and Self-Discipline: Evidence from Inner City Children. Journal of Environmental Psychology, 22, 49-63.

Watt, T. T. (2003). Are small schools and private schools better for adolescents' emotional adjustment? Sociology of Education, 76, 344-367.

Wells, N. M. (2000). At Home with Nature, Effects of "Greenness" on Children's Cognitive Functioning. Environment \& Behavior, 32(6), 775-795.

Wells, N. M., \& Evans, G. W. (2003). Nearby Nature: A Buffer of Life Stress Among Rural Children. Environment \& Behavior, 35(3), 311-330. 
Ärlemalm-Hagsér, E. (2006). Gender, playing and learning in natural outdoor environments.

In J. Brodin \& P. Lindstrand (Eds.), Interaction in outdoor play environments :

gender, culture and learning (pp. 98 s.). Stockholm: Stockholm Institute of Education 
Table 1. Demographic information by school $(n=230)$.

\begin{tabular}{|c|c|c|c|}
\hline & $\begin{array}{l}\text { Intervention school } \\
(n=121)\end{array}$ & $\begin{array}{l}\text { Reference school } \\
(n=107-109)\end{array}$ & $\begin{array}{l}\text { Test, } p \text { value of } \\
\text { difference }\end{array}$ \\
\hline Gender, \% girls & 43.8 & 48.6 & $\chi^{2}, n s$ \\
\hline Age, mean (SD) years & $8.6(1.6)$ & $8.1(1.5)$ & t- test, $p=.021$ \\
\hline Socioeconomic status & & & $\chi^{2}, p<.001$ \\
\hline Low, \% & 17.4 & 67.9 & \\
\hline Middle, \% & 41.3 & 22.9 & \\
\hline High, \% & 41.3 & 9.2 & \\
\hline Immigrant parents, \% & 0.0 & 64.5 & $\chi^{2}, p<.001$ \\
\hline
\end{tabular}


Table 2. Descriptive statistics of SDQ scores by time, school and gender $(N=230)$.

\begin{tabular}{|c|c|c|c|c|}
\hline & \multicolumn{2}{|c|}{$\begin{array}{l}\text { Intervention school } \\
\text { (53 girls, } 68 \text { boys) }\end{array}$} & \multicolumn{2}{|c|}{$\begin{array}{l}\text { Reference school } \\
\text { (53 girls, } 56 \text { boys) }\end{array}$} \\
\hline & $\mathrm{T} 1, M(S D)$ & $\mathrm{T} 2, M(S D)$ & $\mathrm{T} 1, M(S D)$ & $\mathrm{T} 2, M(S L$ \\
\hline \multicolumn{5}{|l|}{$\underline{\text { Girls }}$} \\
\hline Total Difficulties & $4.1(3.0)$ & $4.3(3.4)$ & $7.1(4.6)$ & $6.6(4.1)$ \\
\hline Emotional symptoms & $1.4(1.4)$ & $0.9(1.2)$ & $2.0(1.6)$ & $1.5(1.8)$ \\
\hline Conduct problems & $0.7(0.9)$ & $0.7(1.0)$ & $1.3(1.3)$ & $0.9(0.9)$ \\
\hline Hyperactivity & $1.5(1.4)$ & $2.0(1.9)$ & $2.5(2.3)$ & $2.2(2.1)$ \\
\hline Peer problems & $0.5(1.0)$ & $0.6(1.1)$ & $1.3(1.3)$ & $1.9(1.6)$ \\
\hline Prosocial behaviour & $8.8(1.6)$ & $8.5(1.9)$ & $8.7(1.5)$ & $8.7(1.3)$ \\
\hline
\end{tabular}

$\underline{\text { Boys }}$

$\begin{array}{lllll}\text { Total difficulties } & 6.4(4.6) & 5.0(4.6) & 9.6(6.3) & 11.0(6.6) \\ \text { Emotional symptoms } & 1.2(1.3) & 0.8(1.2) & 2.2(2.0) & 2.7(2.3) \\ \text { Conduct problems } & 1.4(1.4) & 1.0(1.3) & 1.6(1.6) & 1.8(1.5) \\ \text { Hyperactivity } & 2.8(2.3) & 2.5(2.4) & 3.5(2.5) & 3.9(2.4) \\ \text { Peer problems } & 0.9(1.3) & 0.8(1.2) & 2.3(2.1) & 2.6(2.5) \\ \text { Prosocial behaviour } & 8.5(1.7) & 8.3(1.9) & 8.3(2.0) & 7.6(2.0)\end{array}$

Note. SDQ = The Strengths and Difficulties Questionnaire, T1 = Time 1, Initial assessment, T2 = Time 2, 1-year follow-up. 
Table 3. Summary of the main results of effects of gender on intervention outcome.

Stochastic and quantitative estimates of the experimental effects for the separate Strengths and Difficulties Questionnaire (SDQ) subscales $(N=228)$.

\begin{tabular}{|c|c|c|c|c|}
\hline \multirow[t]{3}{*}{ SDQ score } & \multicolumn{4}{|c|}{ Time $\times$ School $\times$ Gender effect } \\
\hline & \multirow[t]{2}{*}{ Partial $\eta^{2 a}$} & \multirow[t]{2}{*}{$p$ value $^{\mathrm{a}}$} & \multicolumn{2}{|c|}{ Effect size $\mathrm{e}^{\mathrm{b}}$ by gender } \\
\hline & & & Girls & Boys \\
\hline Total difficulties & .049 & .001 & -0.17 & 0.51 \\
\hline Emotional symptoms & .018 & .044 & 0.01 & 0.59 \\
\hline Conduct problems & .040 & .003 & -0.32 & 0.42 \\
\hline Hyperactivity & .036 & .005 & -0.48 & 0.28 \\
\hline Peer problems & .000 & ns & 0.27 & 0.29 \\
\hline Prosocial behaviour & .009 & ns & 0.17 & -0.21 \\
\hline
\end{tabular}

Note. Positive effect sizes indicate a positive change (decrease in psychiatric symptoms or in the case of prosocial behaviour increase in competence). $n s=$ not significant, $p>.10$

${ }^{a}$ Adjusted for socioeconomic status and immigrant parents

${ }^{\mathrm{b}}$ Not adjusted for covariates 